\title{
EDITORIAL
}

\section{HISTORIA, ARCHIVO Y MULTIDISCIPLINA EN CHILE*}

\author{
Rodrigo Ruz Zagal** \\ Luis Galdames Rosas***
}

HISTORY, ARCHIVES AND MULTIDISCIPLINARY IN CHILE

La historia, entendida como un área del conocimiento que circula entre las humanidades y las ciencias sociales, desde mediados del siglo XX ha venido caracterizándose en su transitar por necesarios matices. A nivel disciplinar, conocidos son los denominados "giros" bidireccionales hacia la antropología, lingüística, semiología, visualidades y enfoques críticos (Noiriel 1997).

De éstos, considerando sus avances y retrocesos paradigmáticos a nivel mundial, resulta más o menos claro que no solo la historia, sino que la totalidad de las especialidades que atienden temáticas referentes al ser humano, la sociedad y su cultura, han visto remecidos sus cimientos epistemológicos tradicionales, primando en ellas los cambios (Breisacht 2009).

En este contexto, la historia ha ido manifestando importantes renovaciones en su teoría y método, característica evidente y transversal en su vertiente científica (en lo metódico), pero también desarrollada en las miradas hermenéuticas. Este cambio enfrenta concepciones y tradiciones investigativas historiográficas que parafraseando a Michel de Certeau (1975) responden a "dos posiciones frente a lo real", una que accede a la "realidad" de sociedades pretéritas "resucitándolas" con intención objetiva; y otra que construye "la realidad" mediante un relato afectado por la subjetividad de quien le otorga sentido (Ricoeur 1990).
Independientemente de estos sanos enfrentamientos, que sin duda diversifican la idea de la historia sumando seguidores y formando escuelas de una u otra línea ${ }^{1}$, hay elementos estructurantes respecto su quehacer que nunca han sido perdidos de vista. Uno de ellos, sino el más importante, refiere a la necesidad de contar con una materialidad que represente una realidad social, cultural, política o institucional en dimensiones objetivas, pero también subjetivas e intersubjetivas.

Esta necesidad es la que posiciona al archivo como elemento ancla para la historia (y sus distintas acepciones) siendo el registro del pasado y su interlocución el soporte donde esta edifica sus modelos de análisis y de comprensión.

El archivo, entendido en su versión moderna como el conjunto de testimonios, huellas, símbolos, monumentos, imágenes o sonidos, organizados con carácter de unidad, posee para la historia una dimensión polisémica que a pesar de parecer compleja por las diversas interpretaciones que se le pudiesen dar a una representación del pasado, también posee en su dimensión y función investigativa un incontrarrestable carácter materialista que evidencia -para algunos- un molesto pecado original anclado al positivismo, característica que responde a la más profunda tradición historiográfica, que pese a la zozobra ocurrida hacia la medianía del siglo XX con la caída de la vieja concepción de ciencia, se ha

\footnotetext{
Publicación producida en el marco del proyecto FONDECYT 1151514 y Convenio de Desempeño en Educación Superior Regional UTA 1401, financiado por el Ministerio de Educación y la Universidad de Tarapacá.

** Universidad de Tarapacá. Departamento de Ciencias Históricas y Geográficas. Director Archivo Histórico Vicente Dagnino. Correo electrónico: rruz@uta.cl.

*** Universidad de Tarapacá. Departamento de Ciencias Históricas y Geográficas. Correo electrónico: 1galdame@uta.cl

1 Definiendo trayectorias historiográficas "sectoriales" reflejadas en parcelas como la historia social, demográfica, económica, marxista, sociológica, antropológica, de las mentalidades o cultural; y especializaciones que apelan a una "renovación" de enfoques a partir del desarrollo de adjetivos que circulan entre abordajes de género, medio ambiente, regional/local, microhistoria, historia de la vida cotidiana e historia del tiempo presente (Hernández 2004).
} 
visto fortalecida a partir de la hegemonía occidental de los paradigmas neopositivistas, racional crítico e incluso el neomarxista que vinieron a apuntalar la decaída tradición científica (Cruz 2008).

La veta investigativa de la historia sugiere la importancia del archivo como rector de su naturaleza científica, advirtiendo que si bien el pasado no se presenta al historiador como objeto, sí se "observa" en sus huellas documentales, relevando la figura del historiador como un sujeto cognoscente que a partir de problemáticas del presente analiza al pasado intentando encontrar su esquivo sentido. De este modo la racionalidad hipotética centrada en la importancia del problema de investigación (en clave científica) o bien en la pregunta trascendental (en términos filosóficos y humanistas) rige el quehacer del historiador.

La hegemonía de estos modelamientos epistemológicos ha tornado cada vez más ineludible el uso de materialidades del pasado, situación por la que la naturaleza del archivo posee una vigencia y valor no menor en una época donde es demandado como objeto legitimador de postulados científicos, así como también en reafirmaciones o apropiaciones subjetivas o colectivas respecto del pasado, demandadas por la ciudadanía y por especialidades que escapan al prototipo de las ciencias, pero que requieren de materialidad para adquirir valor testimonial.

Estas últimas vertientes asociadas a la hermenéutica han ornamentado al archivo y sus materialidades de un tenor "artefactual" que amplía la cobertura y alcances de los estudios históricos, rompiendo con ello el tradicional enfoque heurístico, superando también el concepto de "fuente", acrecentando con ello sus miradas hacia el pasado apelando a fenómenos memorísticos que relativizan el pasado objetivo, concentrando sus análisis en interpretación de testimonios, huellas, indicios y sus archivos, con acento en sus contextos de producción, circulación, lecturas, narración y textualidad de sus formas (Hernández 2004).

Este último foco-que compartimos- es particularmente visible en la denominada historia cultural, la que requiere para sus análisis de elementos que objetiven la producción del ser humano: instrumentos (artefactos), bienes, técnicas, procedimientos, hábitos y más complejamente ideas, valores, fantasías, creencias e incluso silencios.

Esta complejidad marca la importancia, pero también el desafío que deben enfrentar los historiadores que circulan en torno a los archivos como objeto de estudio, ya que existe una suerte de obligación de establecer puentes interdisciplinarios, normalmente evidenciables en el uso de conceptos o marcos teóricos provenientes de preferencia de la teoría social, para alimentar hipótesis que rompan el carácter descripitivo del quehacer histórico por tradición entendido, o bien generar lazos, formar equipos y programas de investigación que permitan abordar de modo multiescalar las problemáticas socioculturales que se objetivan en soportes complejos a los que los historiadores poco se acostumbran a desarrollar con método y técnicas propias.

A nivel regional y macrorregional (Chile y el espacio centro sur andino), los guiños entre la historia y otras disciplinas en función de otorgar una mayor preponderancia hacia los elementos difíciles de objetivar en torno a la cultura, han tejido un entramado multidisciplinar que define vínculos entre la historia y la antropología cultural, los estudios culturales, andinos, visuales y del arte, la sociosemiótica, semiología y estudios en torno a los mass media, de manera preferente. Ello, sin dejar de mencionar el vínculo con especialidades como la archivística, la conservación, restauración y la patrimonialización de las materialidades, que también han manifestado un desarrollo no menor y con alto estándar técnico, resultante de la demanda al archivo del nuevo canon (Seguel 2013).

La multiplicación en Chile de los archivos y la investigación multidisciplinaria en torno a ellos se encumbra a partir del retorno a la democracia, en la década de 1990, considerando que el momento previo estuvo de modo indudable marcado negativamente por la dictadura militar que, en distintos grados afectó el desarrollo académico de las humanidades, ciencias sociales y artes, pero también marcó de manera dramática la forma en cómo la ciudadanía se vinculó al pasado.

Con progresión y en la medida que la política de transición a la democracia se fue desapegando de los temores golpistas, y que las universidades con foco humanista y social fueron adquiriendo un desarrollo académico liberador de las inercias autoritarias posdictadura, la investigación respecto del pasado ha ido con progresión proliferando, sumándose a las tradicionales facultades universitarias de naturaleza pública en historia, ciencias sociales y artes en Chile; otras nuevas que han sabido recoger los cambios disciplinares antes señalados. Entrado el siglo XXI la incorporación de nuevos investigadores con formación doctoral especialmente en el 
extranjero, han venido a fortalecer los tradicionales programas en estas especialidades.

Investigadores y especialistas incorporados, así como los que se han formado y madurado a los aleros de programas académicos nacionales, se han situado y posicionado como intelectuales orgánicos o gestores dentro de sus instituciones y dentro de las comunidades en las que se desenvuelven, generando con ello un círculo virtuoso respecto del pasado, su archivo y su investigación. Es por ello que en los últimos tiempos también han proliferado, mejorado estándares y aperturas de colecciones, no solo archivos, sino también museos, centros de documentación y repositorios (incluyendo digitales).

De esta manera a los tradicionales archivos de naturaleza arcóntica asociados a estructuras administrativas que organizaron y organizan el quehacer de los Estados se han sumado otros de naturaleza investigativa ${ }^{2}$, memorística, patrimonial y con funcionalidad a la ciudadanía, e incluso con orientación contemplativa conducente a provocar goce estético (Barriendos 2012).

A la implementación de una política estatal respecto de la transparencia y acceso a fondos documentales públicos, se han sumado varios emprendimientos respecto de archivos, siendo no menor el número de proyectos con financiamiento público y privado que una vez ejecutados disponen de un corpus sistemático de materialidad diversa que no solo se perfila como un repositorio pasivo, sino que también propone una forma performáticamente elaborada de vincularse con el pasado.

Esta celeridad también posee cuestionamientos importantes, surgidos preferentemente de quienes ponen en duda las motivaciones del por qué y para qué archivar, custodiar e incluso recordar. Apelativos académicos respecto del uso político del pasado no escasean: "obsesión conmemorativa" (Traverso 2007), "furor de archivo" (Rolnik 2010), "sobreabundancia melancólica del pasado" (Meier 1993), "saturación de memoria" (Robin 2003), entre muchos otros adjetivos conceptualizados, no dejan de ser respetables y reflejan una sana presencia del pasado en el tiempo presente, su estudio y necesaria reflexión especialista.

El presente número de Diálogo Andino viene a entregar un cuerpo significativo de trabajos relativos

Esto es, archivos creados en función de problemas de investigación puntuales (Ver González y Artaza 2015 en este número). al primero de los paradigmas discutidos en este editorial, reuniendo investigaciones sistemáticas y de diversas especialidades que, como hemos señalado, recogen el guante respecto de la nueva forma de entender el archivo, abarcando aspectos que van desde su abordaje científico, sin clausurar el imperativo humano que caracteriza el desarrollo actual de la práctica historiográfica y de las ciencias sociales.

En gran parte, los trabajos expuestos en este número se concentran en la mirada antropológica respecto del archivo, circulando en los enfoques etnohistóricos, antropológicos (etnográficos) e histórico-culturales que han desarrollado con mayor profundidad y apertura programática su especialidad en el espacio andino sudamericano preferentemente.

No es casual que en un número levantado sobre la base de una convocatoria realizada por Diálogo Andino y desde la Universidad de Tarapacá, situada en el extremo norte chileno, poseedor de una linealidad histórica hundida en lo prehispánico y con una profunda impronta multiétnica, pluricultural y de vida fronteriza en los Andes, no hiciera resonancia en quienes desarrollan investigación en sociedades indígenas andinas actuales y pretéritas. Este número posee dicho sello.

Diálogo Andino abre este número con la investigación desarrollada por parte de una de las más importantes especialistas en temas referentes al poder escritural y rol del registro escrito en su dimensión social y apropiación cultural en contextos coloniales y actuales en los Andes. La profesora Joanne Rappaport del Departamento de Español y Portugués de la Georgetown University colabora con su inédito trabajo Letramiento y mestizaje en el Nuevo Reino de Granada, siglos XVI y XVII, en donde se evalúa el trasfondo intencionado de la clasificación sociorracial en el pasado de la actual Colombia, que construida sobre la base de epistemologías letradas y procedimentalmente escritas, ejercía dominación y estimulaba segmentación entre grupos humanos indios, mestizos, negros e hispanos a manos del estado colonial.

En el mismo tenor y con temáticas similares, que también denotan un trabajo con trayectoria, madurez programática en torno a la problematización de formatos escriturales predominantes en contextos coloniales y de frontera, Lidia Nacuzzi, en coautoría con Carina Lucaioli, ambas de la Universidad de Buenos Aires, exponen Declaraciones de cautivos: piezas de archivo multivocales de la frontera colonial 
(virreinato del Río de la Plata, siglo XVIII), en este trabajo se otorga una dimensión etnográfica al registro escritural del pasado, pesquisando intencionalidades y representaciones subalternizadas en documentación pauteada y formateada por burócratas del estado colonial español, en torno a la situación de personas cautivas preferentemente por indígenas en el virreinato de la Plata, instancia que ofrece una interesante perspectiva respecto de los contextos de vida de sujetos y colectivos subrepresentados o marginalizados en la documentación producida bajo estos contextos.

Mención aparte en este número lo requiere el aporte reflexivo otorgado por Tristan Platt respecto al balance de los estudios en y sobre archivos en el área andina. Esta colaboración titulada Entre la rutina y la ruptura. El archivo como acontecimiento de terreno, fue especialmente requerida al profesor Platt por los editores, atendiendo la honestidad, claridad y profundidad de un artículo ya publicado, pero que había permanecido limitado en su circulación ${ }^{3}$. Diálogo Andino por medio de su indización SciELO busca ampliar la cobertura de este al mundo.

En similar calidad reflexiva, la profesora de Antropología y Estudios Históricos de New School for Social Research de New York, Ann Stoler, excepcionalmente nos envió su conferencia On archival labor. Recrafting colonial history realizada ante la Asociación de Archiveros de las Antillas Holandesas con motivo de homenajear al estructurador de vínculos entre la historia, etnología y archivos Eric Ketelaar. Su intervención se presenta en calidad de Addendum y recoge ideas y balances respecto de la importancia de los archivos en contextos coloniales y postcoloniales, con una sincera advertencia metodológica y epistemológica.

Los aportes nacionales a Diálogo Andino son abiertos con el trabajo del actual Premio Nacional de Historia, Sergio González de la Universidad Arturo Prat que en coautoría con Pablo Artaza de la Universidad de Chile, presentan el trabajo Cateando la palabra. La construcción de nuevos archivos sobre

\footnotetext{
Artículo originalmente publicado en inglés bajo el título Between routine and roupture: the archives as field-event, en Handbook of social anthropology, Vol. II. Sage publications Ltd, Londres, Inglaterra (2012). Posteriormente publicado en Los Estudios Andinos hoy. Práctica intelectual y estrategias de investigación, en Carlso Zanolli et al. (compiladores) Prohistoria ediciones, Rosario, Argentina (2013).
}

la sociedad del salitre, en donde desde la madurez de quien realiza investigación programática en torno al mundo salitrero, se manifiesta la necesidad de construir y constituir nuevos registros y archivos. $\mathrm{La}$ edición del presente número invitó a los profesores González y Artaza a retomar esbozos planteados por el primero el 2006, momento en que se publicó el libro Pampa Escrita. Cartas y fragmentos del desierto salitrero, donde se trabajó acerca de una cantidad importante de la producción epistolar de hombres y mujeres que reflejaron sus afectos y temores en el desierto de Tarapacá. Apelando a la novedad y valor disciplinario de esta experiencia, ambos autores profundizaron acerca de la importancia no solamente testimonial, sino que en la órbita investigativa y que dentro de la práctica científica posee el archivo.

Del Director del Archivo Etnográfico de la Universidad de Chile, académico del Departamento de Antropología de la misma casa de estudios, André Menard, el artículo La etnohistoria, el suplemento y la superstición busca tornar visibles registros o archivos que escapan a la noción tradicional de estos, a partir del relevamiento de registros normalmente subvalorados (como lo son las "supersticiones"), que al no ser tomadas en cuenta evidencian el escaso rango de acción disciplinar histórico-antropológico tradicional, requiriendo de otras sensibilidades y artes para atender realidades que involucren saberes y sentidos indígenas.

El espacio andino regional del Norte chileno marca su presencia a partir de dos trabajos imbricados pero diferentes, que surgen del programa de investigación iniciado en la década de 1970 por el incansable profesor Jorge Hidalgo. Las publicaciones de Francisca Urrutia del programa de postgrado en antropología de la Universidad de Tarapacá y Mauricio Uribe de la Universidad de Chile titulado Identidad cultural, memoria social y archivos parroquiales (siglos XVIII-XIX): reflexiones etnológicas a partir de una experiencia en Belén (Arica, Norte de Chile), y de Xochitl Inostroza del programa de doctorado en historia de Chile de la Universidad de Chile en coautoría con el propio profesor Hidalgo Parroquia de Belén: familias, archivos, memorias, escalan referente a los trabajos que normalmente caracterizaban al programa "Historia de pueblos andinos" dirigido por Hidalgo, estableciendo vínculos contemporáneos con las comunidades de origen del espacio precordillerano de Arica, en especial en el poblado 
de Belén. Dos enfoques distintos, uno con acento etnográfico y otro con fortalezas históricas y mnemotécnicas que dan cuenta de un salto importante de versatilidad en cuanto a temáticas y nuevos problemas en el espacio andino de Arica.

Como complemento a los escalamientos programáticos señalados en el párrafo anterior, los investigadores Alberto Díaz, Germán Morong y Carlos Mondaca, bajo el título Entre el Archivo y la Etnografía. Reflexiones Historiográficas desde la Periferia del Norte de Chile, sistematizan la experiencia investigativa atingente a problemáticas, histórico-culturales y antropológicas, concentradas en un eficiente trabajo de campo y vínculos con comunidades indígenas de la cordillera de la Región de Arica, Parinacota y Tarapacá, con materialidad documental y archivos locales. Este artículo rescata la experiencia iniciada a fines del siglo XX por parte del Taller de Investigaciones Culturales (TINCU), constituido por -entonces- estudiantes de Historia y Geografía de la Universidad de Tarapacá y que hoy gracias a dicha experiencia dirigen proyectos y programas de investigación. Esta edición de Diálogo Andino reserva este espacio para dar cuenta del trabajo acumulado en años, pero que ha permanecido relativamente invisibilizado al tratarse de experiencias académicas que al ser regionales, con escasez repercuten en las comunidades especialistas a nivel nacional e internacional. En este sentido Diálogo Andino espera ampliar la extensión y divulgación de su trabajo.

Los académicos de la Universidad de Tarapacá Carlos Choque y Alberto Díaz presentan el artículo El archivo familiar de Modesto Mena como tecnología simbólica. Identidades, conflictos y memorias colectivas en los Altos de Arica, que otorga importancia al archivo personal de un sujeto andino (registros escasos y de invaluable potencial cualitativo), en cuanto al impacto que genera su uso y artefactualización en contextos de conflicto intra y extracomunitario por parte de una comunidad de la precordillera ariqueña (Ticnamar), situación extrapolable a otras colectividades. La práctica respecto del uso de archivos fortalecería la cohesión social de estos grupos reafirmando también sus identidades colectivas frente a cambios culturales e ideológicos.
De la misma Universidad de Tarapacá, Héctor González, perteneciente al Departamento de Antropología, y Rodrigo Ruz, del Departamento de Ciencias Históricas y Geográficas, evalúan el impacto generado en comunidades altiplánicas de Arica y Parinacota por las lógicas jurídicas y estatales respecto de la definición de la propiedad privada en espacios comunitarios iniciado el siglo XX por parte del Estado chileno. El artículo Fe en el papel: la inscripción del dominio de las tierras de comunidad en el altiplano chileno otorga proyecciones importantes respecto de la forma en que la propiedad privada afectó patrones tradicionales aymara de ocupación del espacio en sus dimensiones familiares, económicas y de vínculo entre sujetos, colectividades y Estado.

Finalmente, Luis Galdames reseña el libro Archivo Fotográfico. Manuel Yanulaque Scorda (1850-1934). Historia e imágenes ariqueñas de ediciones Universidad de Tarapacá en conjunto con el Consejo Nacional de la Cultura y las Artes, poniendo en relieve una publicación regional que, bajo sello universitario, desarrolla temáticas referidas a archivo y fotografía, que va más allá del mero registro y sistematicidad archivística, abordando aspectos relativos a la memoria, visualidades y enfoques biográfico-casuísticos, sin dejar de lado la importancia de vincular el pasado con la sociedad actual. Esta publicación también pretende relevar el rol que juega el Archivo Histórico Vicente Dagnino, dependiente del Departamento de Ciencias Históricas y Geográficas de la Universidad de Tarapacá, institución que por más de 30 años ha sido custodia de parte del patrimonio documental regional de la sociedad inscrita en la Región de Arica y Parinacota.

A modo de sumario, esta edición de Diálogo Andino es inclusiva en cuanto a la diversidad de perfiles investigativos de sus colaboradores, apelando al diálogo multi e interdisciplinar con que se abordan sus problemáticas, sin dejar de observar las trayectorias de quien presenta trabajos en el presente número.

Prima sobre todo una hebra que entrama un tejido en donde la pulsión del pasado y su compleja relación con el presente por medio de su registro y archivo marca cada una de las obras y trabajos expuestos. 


\section{Referencias Citadas}

Barriendos, Joaquín

2012 Reterritorializando los sesenta. Archivo, documentos y postestructuralismo en el museo de arte. En Alejandra Castillo y Cristián Gómez-Moya (editores) Arte, archivo y tecnología: 121-139. Universidad Finis Terrae, Chile.

Breisach, Ernst

2009 Sobre el futuro de la historia. El desafio postmodernista y sus consecuencias. Publicacions de la Universitat de València, España.

Cruz, Manuel

2008 (1991) Filosofía de la Historia. Alianza editorial, España.

De Certeau, Michel

2006 (1975) La escritura de la Historia. Universidad Iberoamericana-Instituto Tecnológico y de Estudios Superiores de Occidente, México.

Hernández, Elena

2004 Tendencias historiográficas actuales. Escribir historia hoy. AKAL. España.
Meier, Charles

1993 A surfeit of memory? Reflections on history, melancoly and denial. En History \& Memory 5: 136-152.

Noiriel, Gérard

1997 Sobre la crisis de la historia. Frónesis Cátedra Universitat de València, España.

Ricoeur, Paul

1990 (1955) Historia y verdad. Encuentro Ediciones, España.

Robin, Régine

2003 La mémoire saturée. Stock, Francia.

Rolnik Suely

2019 Furor de Archivo. Estudios Visuales 7: 115-130.

Seguel, Roxana

2013 Editorial. Conserva 18: 2-4.

Traverso, Enzo

2007 Historia y Memoria. Notas sobre un debate. En Marina Franco y Florencia Levín (editores), Historia reciente. Perspectivas y desafíos para un campo en construcción: 67-96. Editorial Paidós, Argentina. 